\title{
Ação do suco do fruto de Morinda citrifolia L. em células de sistema-teste vegetal
}

\author{
Gleuvânia Marques \\ Ellifran Bezerra de Siqueira Dantas \\ Ana Paula Peron* \\ Núcleo de Pesquisa Aplicada a Saúde e ao Meio-ambiente \\ Laboratório de Citogenética Vegetal e Animal, Universidade Federal do Piaú \\ Rua Cícero Duarte, 940, Junco, Campus Senador Helvídio Nunes de Barros \\ CEP 64600-940, Picos $\square$ PI, Brasil \\ * Autor para correspondência \\ anpapegenpes@yahoo.com.br
}

Submetido em 12/05/2013

Aceito para publicação em 31/11/2013

\section{Resumo}

Neste estudo, avaliou-se a ação do suco de noni sobre as células meristemáticas de raízes de Allium cepa, em duas concentrações, 0,18 e $0,36 \mathrm{mg} / \mathrm{mL}$, com os tempos de exposição de 24 e $48 \mathrm{~h}$. Para cada concentração se utilizou um grupo de 5 bulbos de cebolas, que primeiramente foram inseridos em água destilada e, em seguida, transferidos para suas respectivas concentrações. As radículas foram coletadas e fixadas em ácido acético (3:1) por $24 \mathrm{~h}$. As lâminas foram preparadas pela técnica de esmagamento, e coradas com orceína acética a $\%$. Foram analisadas células em todo ciclo celular, totalizando 5.000 para cada controle e tempo de exposição. Os índices mitóticos calculados foram submetidos à análise estatística de qui-quadrado $(\mathrm{p}<0,05)$. Verificou-se que ambas as concentrações, inclusive a menor, considerada ideal para consumo, aumentou de forma significativa o índice mitótico das células meristemáticas de raízes de cebola. Portanto, nas condições analisadas, ambas as concentrações testadas do suco de noni promoveram alteração na divisão celular desse sistema-teste vegetal.

Palavras-chave: Divisão celular; Noni; Planta medicinal; Raízes de Allium cepa

\section{Abstract}

Action of the juice from the fruit of Morinda citrifolia L. on cells of the plant test system. In this study, we evaluated the action of noni juice on the meristematic cells of Allium cepa roots, at two concentrations, 0.18 and $0.36 \mathrm{mg} / \mathrm{mL}$, with the exposure times of 24 and $48 \mathrm{~h}$. For each concentration, we used a group of 5 onion bulbs, which were first embedded in distilled water and, then, transferred to their respective concentrations. The radicles were collected and fixed in acetic acid (3:1) for 24 hours. The root tips were collected and fixed in acetic acid $(3: 1)$ for $24 \mathrm{~h}$. The slides were prepared through the crushing technique, and stained with $2 \%$ acetic orcein. Cells were analyzed throughout the cell cycle, totaling 5,000 for each control and exposure time. The mitotic indices calculated underwent chi-square $(\mathrm{p}<0.5)$ statistical analysis. We found out that both concentrations, including the lowest, regarded as ideal for consumption, significantly increased the mitotic index of meristematic cells of onion roots. Therefore, under the analyzed conditions, both tested concentrations of noni juice have promoted change in the cell division of this plant test system.

Key words: Allium cepa roots; Cellular division; Medicinal plant; Noni 


\section{Introdução}

O fruto da árvore $M$. citrifolia (Rubiaceae) variedade citrifolia, conhecido como noni, é comumente consumido na forma de suco pela população das Américas e Europa para a prevenção e amenização de doenças como alergias da pele e do sistema respiratório, artrite, depressão, câncer do trato digestório e diabetes, e também como suplemento alimentar, analgésico, antibactericida, antiviral, hipotensivo e antioxidante (WESTENDORF et al., 2007; BASAR et al., 2010).

De acordo com a European Food Safety $\square$ EFSA (2009), na composição química deste fruto encontramse os ácidos caproicos, caprílico, ascóbico; o alcaloide xeronina; fibras; os sais minerais potássio, cálcio, fósforo e selênio; os alcóois 3-metil-3-butenol; os estéres metil octanato e metil decanoato; cetonas, principalmente as de sete carbonos; lactonas; e grande concentrações de antraquinonas e de vitamina $\mathrm{C}$.

As raízes e as folhas de $M$. citrifolia já foram amplamente estudadas quanto a sua atividade em nível celular, e alguns estudos mostraram que extratos aquosos e alcóolicos preparados a partir destas partes da planta têm potencial citotóxico em função, principalmente, das antraquinonas presentes em suas constituições fitoquímicas (BASAR et al., 2010). Diferentemente, ainda são escassos os estudos sobre a ação em nível celular do suco do fruto desta espécie vegetal.

O sistema teste vegetal Allium cepa é um excelente bioindicador de toxicidade de plantas medicinais em nível celular devido as suas propriedades cinéticas de proliferação, por possuir cromossomos grandes e em número reduzido $(2 \mathrm{n}=16)$ (FACHINETTO et al., 2007), e também pela confiabilidade e concordância com outros testes de toxicidade, auxiliando grandemente os estudos de prevenção à saúde humana (LEME; MARINMORALES, 2009).

Assim, em virtude do consumo do suco de noni pela população, bem como a necessidade de estudos sobre sua ação em nível celular, e considerando o sistema $A$. cepa adequado para este tipo de avaliação este trabalho teve por objetivo avaliar duas concentrações do suco de noni, obtidos segundo sua utilização popular, em células meristemáticas de raízes de $A$. сеpa em dois tempos de exposição.

\section{Materiais e Métodos}

Para a realização deste trabalho frutos da planta M. citrifolia foram coletados em um horto medicinal localizado na cidade de Teresina, Estado do Piauí, no mês de maio de 2012. A identificação da planta e a coleta dos frutos foram realizadas pela Prof ${ }^{\mathrm{a}}$ Maria do Socorro Meireles de Deus, mestre em botânica e docente da Universidade Federal do Piauí.

Para a avaliação da ação em nível celular, estabeleceu-se duas concentrações do suco de noni, a de 0,18 mg/mL, que de acordo com Basar et al. (2010) é a mais utilizada pela população, e outra duas vezes maior, de $0,36 \mathrm{mg} / \mathrm{mL}$. Para o preparo dos sucos, polpas in natura destes frutos foram trituradas em água e em seguida coadas. É importante ressaltar que os sucos foram feitos da mesma forma como a população os prepara.

Os bulbos de Allium cepa foram colocados para enraizar em frascos com água destilada, à temperatura de $25^{\circ} \mathrm{C}$ e aerados constantemente, até a obtenção de raízes com cerca de $1 \mathrm{~cm}$ de comprimento. Para análise de cada concentração estipulou-se um grupo experimental com cinco bulbos de cebolas.

Antes de se colocar as raízes em contato com as suas respectivas concentrações, algumas raízes foram coletadas e fixadas para servirem de controle (CO) do próprio bulbo. Em seguida, as raízes restantes foram colocadas em suas respectivas concentrações, por 24 h, procedimento este denominado de tempo de exposição $24 \mathrm{~h}$ (TE $24 \mathrm{~h})$.

Após este tempo foram retiradas algumas raízes e fixadas. Feito este procedimento, as raízes restantes de cada bulbo foram devolvidas as suas respectivas concentrações onde permaneceram por mais $24 \mathrm{~h}$, o que se denominou de tempo de exposição 48 h (TE 48 h). Após este período, raízes novamente foram coletadas e fixadas. Os tempos de exposição de 24 e $48 \mathrm{~h}$ foram escolhidos com o intuito de se avaliar a ação das concentrações estudadas em mais de um ciclo celular. 
A fixação das raízes se deu em Carnoy 3:1 (etanol: ácido acético), a temperatura ambiente, por $24 \mathrm{~h}$. Para cada coleta de raiz, retirou-se, em média, três raízes por bulbo de cebola.

As lâminas, em média três por bulbo, foram feitas seguindo o protocolo proposto por Guerra e Souza (2002). Cada lâmina foi corada com duas gotas de orceína acética a $2 \%$ e analisada em microscópio óptico, em objetiva de 40X. Para cada bulbo analisou-se 1.000 células, totalizando 5.000 células para cada controle e concentração. Durante a análise, observou-se células em interfase, prófase, metáfase, anáfase e telófase. Foi calculado o número de células em intérfase e em divisão de cada controle e tempos de exposições e determinado o índice mitótico que, de acordo com Vicentini et al. (2001), é o número de células em divisão dividido pelo número total de células analisadas.

A análise estatística dos dados foi realizada pelo teste do Qui-quadrado $\left(\chi^{2}\right)$, com nível de probabilidade $<0.05$, por meio do software estatístico BioEstat 3.0 (Ayres, 2007).

\section{Resultados e Discussão}

Muitos compostos que fazem parte da composição química de plantas utilizadas como medicinais podem ser mutagênicos e até carcinogênico quando ingeridos de forma indiscriminada. No entanto, equivocadamente, a cultura popular acredita que fazer o uso indiscriminado de determinada planta não causa mal algum em função de sua origem natural (VARANDA, 2009). O confrei (Symphytum officinale L.) e a carquerja (Baccharis trimera L.) são exemplos de plantas medicinais em que já se observou, em muitos sistemas testes, que em altas concentrações as mesmas promovem alterações significativas no índices de divisão celular. Estas alterações nos índices mitóticos podem ser prejudiciais em função de poderem auxiliar no desencadeamento de atividade mutagênica e carcinogênica, que são extremamente prejudiciais ao organismo (PERON et al., 2008).

$\mathrm{Na}$ Tabela 1, é apresentado o número de células em intérfase e em diferentes fases da divisão celular, e os valores de índice mitóticos obtidos de células meristemáticas de raízes de $A$. cepa tratadas com água e com duas concentrações do suco de noni, nos tempos de exposição de 24 e $48 \mathrm{~h}$.

A partir dos resultados obtidos (Tabela 1), pode se observar que as concentrações do suco de noni testadas, inclusive a considerada usual, aumentaram de forma estatisticamente significativa o índice de divisão celular das células meristemáticas de raízes de A. cepa quando comparadas aos IM obtidos para os seus respectivos controles. Estes resultados mostram que as concentrações avaliadas causaram modificações na divisão celular das células deste sistema teste. Os

TABELA 1: Número de células em intérfase e em diferentes fases da divisão celular, total de células analisadas no ciclo celular de pontas de raízes de $A$. cepa tratadas com água e com as duas concentrações do suco de noni $(0,18$ e $0,36 \mathrm{mg} / \mathrm{mL})$, nos TE $24 \mathrm{e} 48 \mathrm{~h}$.

\begin{tabular}{cccccccccc}
\hline $\begin{array}{c}\text { Concentração } \\
(\mathbf{m g} / \mathbf{m L})\end{array}$ & TE & $\begin{array}{c}\text { Número } \\
\text { de células } \\
\text { analisadas }\end{array}$ & $\begin{array}{c}\text { Células em } \\
\text { interfase }\end{array}$ & $\mathbf{P}$ & $\mathbf{M}$ & $\mathbf{A}$ & $\mathbf{T}$ & $\begin{array}{c}\text { Células em } \\
\text { divisão }\end{array}$ & IM (\%) \\
\hline \multirow{2}{*}{0,18} & $\mathrm{CO}$ & 5.000 & 4329 & 193 & 198 & 187 & 93 & 671 & $13,4^{\mathrm{a}}$ \\
& $24 \mathrm{~h}$ & 5.000 & 3984 & 340 & 287 & 188 & 201 & 1016 & $20,3^{\mathrm{b}}$ \\
& $48 \mathrm{~h}$ & 5.000 & 3903 & 357 & 220 & 278 & 242 & 1097 & $21,9^{\mathrm{b}}$ \\
\hline \multirow{2}{*}{0,36} & $\mathrm{CO}$ & 5.000 & 4352 & 177 & 102 & 192 & 177 & 648 & $12,9^{\mathrm{a}}$ \\
& $24 \mathrm{~h}$ & 5.000 & 3967 & 356 & 315 & 231 & 231 & 1033 & $22,6^{\mathrm{b}}$ \\
& $48 \mathrm{~h}$ & 5.000 & 3806 & 302 & 379 & 244 & 269 & 1194 & $23,8^{\mathrm{b}}$ \\
\hline
\end{tabular}

CO - Controle; TE - Tempo de exposição; P - prófase; M - metáfase; A - Anáfase; T - Telófase; IM - Indice Mitótico. Médias seguidas da mesma letra não diferem significativamente ao nível de $5 \%$ pelo teste do $\chi^{2}$ 
valores de IM de cada concentração nos TE 24 e 48 h não foram significativos entre si. Não foram observadas, para nenhuma das duas concentrações efeitos aneugênicos e aberrações cromossômicas.

Diferentemente dos resultados obtidos aqui, Millong et al. (2005) verificaram que o suco de noni na concentração considerada usual inibiu significativamente a divisão celular de células de fígado humano. Já Westendorf et al. (2007) verificaram que o suco deste fruto, na concentração considerada usual, em cultura de células V79, e em cultura de bactérias Salmonella, linhagem TA1537, não alterou o índice mitótico dos sistemas de prova em questão. Não foram encontrados na literatura outros estudos da ação em nível celular do suco do fruto de $M$. citrifolia.

Apesar de poucos, os resultados sobre a ação do suco de noni sobre o ciclo celular em diferentes sistemas testes mostram-se contraditórios. Assim tornase de maior relevância ainda realizar outros trabalhos de avaliação do suco desta fruta nestas e em outras concentrações, neste e em outros sistemas testes, em diferentes tempos de exposição e diferentes formas de tratamentos para assim se estabelecer quais são as concentrações eficientes e seguras de utilização do suco deste fruto, bem como avaliar, com propriedade, a sua ação em nível celular.

\section{Referências}

AYRES, M. BioEstat 5.0: aplicações estatísticas nas áreas das Ciências Biológicas e Médicas. Brasília: Sociedade Civil Mamirauá, 2007. 364 p.

BASAR, S.; UHLENHUT, T. K.; HOGGER, P.; SCHONE, F.; WESTENDORF, J. Analgesic and antiinflamatory activity of Morinda citrifolia L. (noni) fruit. Phytotherapy Research, London, v. 24, n. 1, p. 38-42, 2010.

EFSA - EUROPEAN FOOD SAFETY AUTORITY. Opinion on the safety of tahitian noni Morinda citrifolia (noni) fruit puree and concentrate as a novel food ingredient. The European Food Safety Autority Journal, London, v. 998, p. 1-16, 2009.

FACHINETTO, J. M.; BAGATINI, M. D.; DURIGON, A. C. F. S.; TEDESCO, S. B. Efeito anti-proliferativo das infusões de Achyrocline satureioides DC (Asteraceae) sobre o ciclo de celular de Allium cepa. Revista Brasileira de Farmacognosia, Curitiba, v. 17, p. 49-54, 2007.

GUERRA, M.; SOUZA, M. Como observar os cromossomos: um guia de técnicas em citogenética vegetal, animal e humana. Ribeirão Preto: FUNPEC, 2002. 191 p.
LEME, D. M.; MARIN-MORALES, M. A. Allium cepa test in environmental monitoring: a review on its application. Mutation Research, Amsterdan, v. 682, p. 71-81, 2009.

MILlONIG, G.; STADLMANN, S.; VOGEL, W. Herbal hepatotoxicity: acute hepatitis caused by a Noni preparation (Morinda citrifolia). European Journal of Gastroenterology \& Hepatology, London, v. 17, n. 4, p. 445-447, 2005.

PERON, A. P.; MATTGE, G. I.; CANTAGALLI, L. B.; MARIUCCI, R. G.; VICENTINI, V. E. P. Avalaliação mutagênica das plantas medicinais Baccharis trimera Less e Solanum melongena L. em células de medula óssea de ratos wistar. Revista Brasileira de Biociências, Porto Alegre, v. 6, n. 2, p. 127-130, 2008.

VARANDA, E. A. Atividade mutagênica de plantas medicinais. Revista de Ciências Farmacêuticas Básica e Aplicada, Araraquara, v. 27, n. 1, p. 1-7, 2009.

VICENTINI, V. E. P.; CAMPAROTO, M. L.; TEXEIRA, L. O.; MANTOVANI, M. S. Averrhoa carambola L., Syzyguim cuminii L. Skeels and Cissus sicyoides: medicinal herbal tea effects on vegetal and test systems. Acta Scientiarum, Maringá, v. 23, p. 593-598, 2001.

WESTENDORF, J.; EFFENBERGER, K.; IZNAGUEN, H.; BASAR S. J. Toxicological and analytical investigations of noni (Morinda citrifolia). Journal of Agricutural and Food Chemistry, Washington, v. 55, n. 2, p. 529-537, 2007. 